\title{
Research on high anal fistula: a bibliometric analysis
}

\author{
Xin Li, Congcong Zhi, Yuying Shi, Yicheng Cheng, Lihua Zheng \\ Anorectal Department, China-Japan Friendship Hospital, Beijing, China \\ Contributions: (I) Conception and design: X Li, C Zhi; (II) Administrative support: Y Shi, Y Cheng; (III) Provision of study materials or patients: L \\ Zheng; (IV) Collection and assembly of data: X Li, C Zhi, Y Shi; (V) Data analysis and interpretation: X Li, C Zhi, Y Shi, L Zheng; (VI) Manuscript \\ writing: All authors; (VII) Final approval of manuscript: All authors. \\ Correspondence to: Lihua Zheng. Anorectal Department, China-Japan Friendship Hospital, Beijing 100029, China. Email: btv1262021@163.com.
}

\begin{abstract}
Background High anal fistula (HAF) treatment is more complicated than low anal fistula treatment. Improper treatment can easily affect anal function. The main treatment of HAF is surgery; however, external medicine and systemic medicine may also be used as adjuvant treatments. This study used bibliometric methods to analyze the relevant literature and provide a rough outline of the current status of HAF research.
\end{abstract} Methods: A subject word-search strategy was used to retrieve HAF-related documents from the Science Citation Index Expanded (SCI-E) database. CiteSpace software was used to analyze the exported raw data files, and draw a visual map, and BUSRT was used to detect and analyze the usage of keywords.

Results: A total of 1,020 documents were retrieved using "high anal fistula" as the search term, and the number of documents generally shows an increasing trend over time. These papers were mainly published in developed countries, such as Europe and the United States (US). The US is the country that has carried out the most relevant cooperative research; however, there is a lack of cooperation among a large number of authors. The keyword analysis showed that the current research focus is the treatment of HAF, while research on the prevention of HAF is largely lacking.

Conclusions: More international multi-center clinical research studies on HAF should be conducted, and research on HAF prevention should also be strengthened.

Keywords: High anal fistula (HAF); surgery; anal function; bibliometric analysis

Submitted Aug 16, 2021. Accepted for publication Nov 09, 2021.

doi: 10.21037/apm-21-3190

View this article at: https://dx.doi.org/10.21037/apm-21-3190

\section{Introduction}

With an incidence of approximately $12-28$ cases per 100,000 people per year, anal fistula is a common perianal disease (1). When other diseases involve the perianal, the incidence of anal fistula is higher $(2,3)$. This disease is more common in young and middle-aged men (1). It causes obvious pain to the patient and significantly affects their quality of life (3). The high anal fistula (HAF) and its branches pass through the levator ani muscle and above the anorectal ring (4). In recent years, the incidence rate of HAF has increased significantly (1). Additionally, the treatment of HAF is difficult, and the recurrence rate is high (1).

The local anatomy and physiological environment of the perianal area is special, which can easily lead to perianal infection, swelling, pain, and the formation of abscesses, which can affect the normal physiological functions of patients. In severe cases, HAF can lead to sepsis, endangering the life and safety of patients. Clinical studies suggest that the pathogenic factors of HAF mainly include anal gland infection, rectal and anus injury, perineal surgery, tuberculosis, ulcerative colitis, and blood infection, and the clinical manifestations mainly include perianal pus, itching, swelling and pain, and systemic symptoms (5). The treatment of HAF is more complicated than that of low anal fistula. Improper treatment can easily affect anal function; thus, choosing an effective treatment method is of great significance in improving clinical efficacy and improving anal function (6). The current clinical research mainly focuses on the surgical treatment of HAF. Careful 
examination before surgery is necessary. The most used examinations include digital examination, magnetic resonance imaging (MRI) and ultrasonography. During the operation, surgeon make further examination by probe to ensure all fistula be found and treated.

At present, the main treatment for HAF is surgery; however, external medicine and systemic medicine are used as adjuvant treatments. There are a variety of surgical procedures for the treatment of HAF, of which sphincter preservation surgery has become the most popular operation (7-9). Common surgical procedures include sphincter-preserving thread-drawing surgery, sliding-flap surgery, transsphincteric fistula ligation (ligation) of the intersphincteric fistula tract (LIFT), video-assisted anal fistula treatment (VAAFT), laser ablation and closure of the anal fistula, and autologous fat-derived stem cell therapy. Though these treatments bring patients high cure rate, some patients still suffer from recurrence. The virtual and actual thread-hanging method proposed by this research group has also achieved good results in the treatment of $\operatorname{HAF}(10)$.

Bibliometrics is a literature research method that has gradually emerged in recent years. It can capture the current status of a specific research field and help researchers to understand the specific field. It can also provide a macro understanding of the research, which can help researchers to choose a reasonable research direction and suitable cooperation objects $(11,12)$. To clarify the current status of research related to HAF, we use bibliometric methods to analyze the basic information of the relevant literature, including the author, the country of the research source, the research institution, and the use of keywords to provide a rough outline of the current status of HAF research.

\section{Methods}

\section{Literature source}

This research used the Science Citation Index Expanded (SCI-E) database in the Web of Science Core Collection (WOSCC), which is commonly used in bibliometrics research, as the data source to search. The SCI-E was established and is published by The Institute for Scientific Information. It contains more than 8,000 important journal paper titles and information cited in the literature. The literature comprises more than 170 natural science articles, including articles in the area of medicine and science. The SCI-E provides a citation retrieval function that allows quantitative analyses of documents in a certain field to be conducted. The SCI-E is an important basis and data source for current bibliometric research and scientific research evaluation.

\section{Retrieval method}

We used a subject term to retrieve documents. The subject term used in this study was "high anal fistula." The publication time for the target documents was not limited; that is, the publication period for the documents ran from the earliest publication date of the database documents [1900] to the final retrieval date of this research (July 25, 2021).

\section{Analysis method}

All the retrieved records were exported, and the bibliographic information was cited in plain-text format to form the original data file. CiteSpace software was used to analyze the exported original data file. The following dimensions were included the analysis: annual changes in the number of publications, trends, annual changes in the number of times a document has been cited, the distribution of the source country and institution, the distribution of the journals published, the distribution of the authors, and the keywords used. The main indicators included the number of documents published per year, the number of citations per year, the number of documents published per country, institutions, and authors, the centrality scores of countries, institutions and authors, and the utility status of keywords.

\section{Statistical analysis}

This study is a descriptive study, and data are expressed in quantities and percentages. No statistical comparisons were conducted; thus, no $\mathrm{P}$ value was set.

\section{Results}

\section{Retrieval results}

A total of 1,150 records (see Table 1) were retrieved in the preliminary search, and 130 duplicate records were eliminated. The actual related research documents totaled 1,020 , and the citation frequency was 25,451 . The average number of citations for each item was 24.95 , and the h-index was 76 (see Table 1). Of the 1,020 documents there were 869 
Table 1 Type of literature

\begin{tabular}{lcc}
\hline Literatures & Records & \% of 1,020 \\
\hline Article & 869 & 85.20 \\
Proceedings article & 120 & 11.76 \\
Review & 108 & 10.59 \\
Letter & 17 & 1.67 \\
Editorial document & 12 & 1.18 \\
Meeting abstract & 12 & 1.18 \\
Early access & 10 & 0.98 \\
Note & 2 & 0.20 \\
\hline
\end{tabular}

The preliminary search result was 1,150 records, after excluding 130 duplicate documents, 1,020 documents remained.

original articles, 120 conferences, 108 reviews, 17 letters, 12 editorial documents, 12 conference abstracts, 10 papers for priority publication, and 2 notes (see Table 1).

\section{Annual changes in the number of documents and the number of citations}

The annual analysis of HAF research documents showed that the number of documents published in this field has generally increased over time, as has the number of citations of these documents (see Table 2, and Figures 1 and 2).

\section{The distribution of countries and institutions}

CiteSpace V software was used to analyze the original data and documents to generate a national visualization map (see Figure 3) that depicts the countries conducting research in this field and their mutual cooperation. The larger the circle representing a country, the more papers that country has published. The number of nodes in the graph was 76, and the relationship between the nodes was 136 . Thus, 76 countries have published research in this field, and 136 cooperative relationships have been established. Similarly, the number of nodes in the organization visualization map was 453 (see Figure 4), and there were 279 interconnections. In terms of the quantitative statistics, the top 5 countries for the number of publications were the United States (US), the United Kingdom, Germany, China, and France (see Table 3). The 5 countries with the top centrality scores were the US, the United Kingdom, Australia, Canada, and Italy (see Table 4). The top 5 institutions for the number of
Table 2 Annual publication of literature on HAF

\begin{tabular}{|c|c|c|}
\hline Years & Records & $\%$ of 1,020 \\
\hline 2021 & 38 & 3.73 \\
\hline 2020 & 60 & 5.88 \\
\hline 2019 & 69 & 6.76 \\
\hline 2018 & 45 & 4.41 \\
\hline 2017 & 52 & 5.10 \\
\hline 2016 & 46 & 4.51 \\
\hline 2015 & 45 & 4.41 \\
\hline 2014 & 40 & 3.92 \\
\hline 2013 & 35 & 3.43 \\
\hline 2012 & 47 & 4.61 \\
\hline 2011 & 54 & 5.29 \\
\hline 2010 & 49 & 4.80 \\
\hline 2009 & 40 & 3.92 \\
\hline 2008 & 41 & 4.02 \\
\hline 2007 & 32 & 3.14 \\
\hline 2006 & 32 & 3.14 \\
\hline 2005 & 22 & 2.16 \\
\hline 2004 & 22 & 2.16 \\
\hline 2003 & 19 & 1.86 \\
\hline 2002 & 23 & 2.25 \\
\hline 2001 & 22 & 2.16 \\
\hline 2000 & 22 & 2.16 \\
\hline 1999 & 15 & 1.47 \\
\hline 1998 & 26 & 2.55 \\
\hline 1997 & 16 & 1.55 \\
\hline 1996 & 25 & 2.45 \\
\hline 1995 & 23 & 2.25 \\
\hline 1994 & 17 & 1.67 \\
\hline 1993 & 13 & 1.27 \\
\hline 1992 & 6 & 0.59 \\
\hline 1991 & 17 & 1.67 \\
\hline 1990 & 1 & 0.10 \\
\hline 1985 & 2 & 0.20 \\
\hline 1984 & 1 & 0.10 \\
\hline 1983 & 2 & 0.20 \\
\hline 1981 & 1 & 0.10 \\
\hline
\end{tabular}

HAF, high anal fistula. 


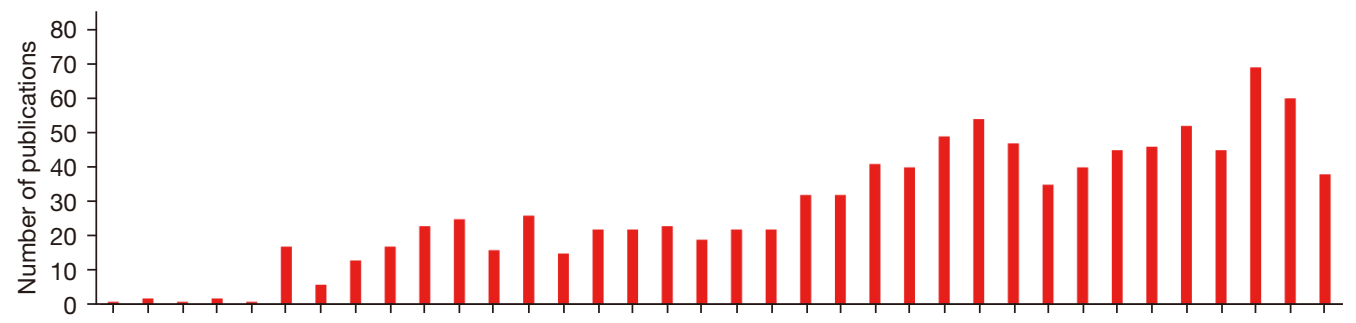

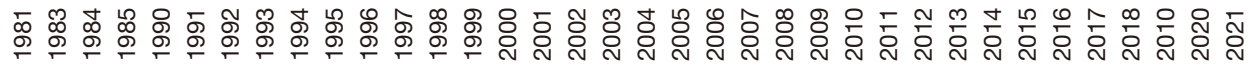
Year

Figure 1 Annual changes in the number of publications.

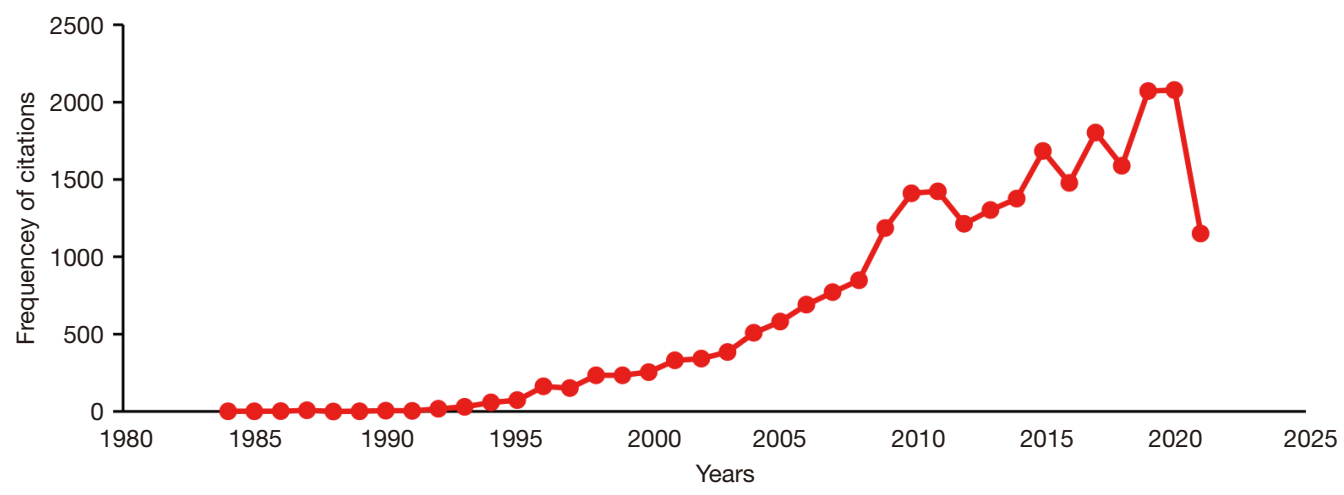

Figure 2 Annual changes in the frequency of citations.

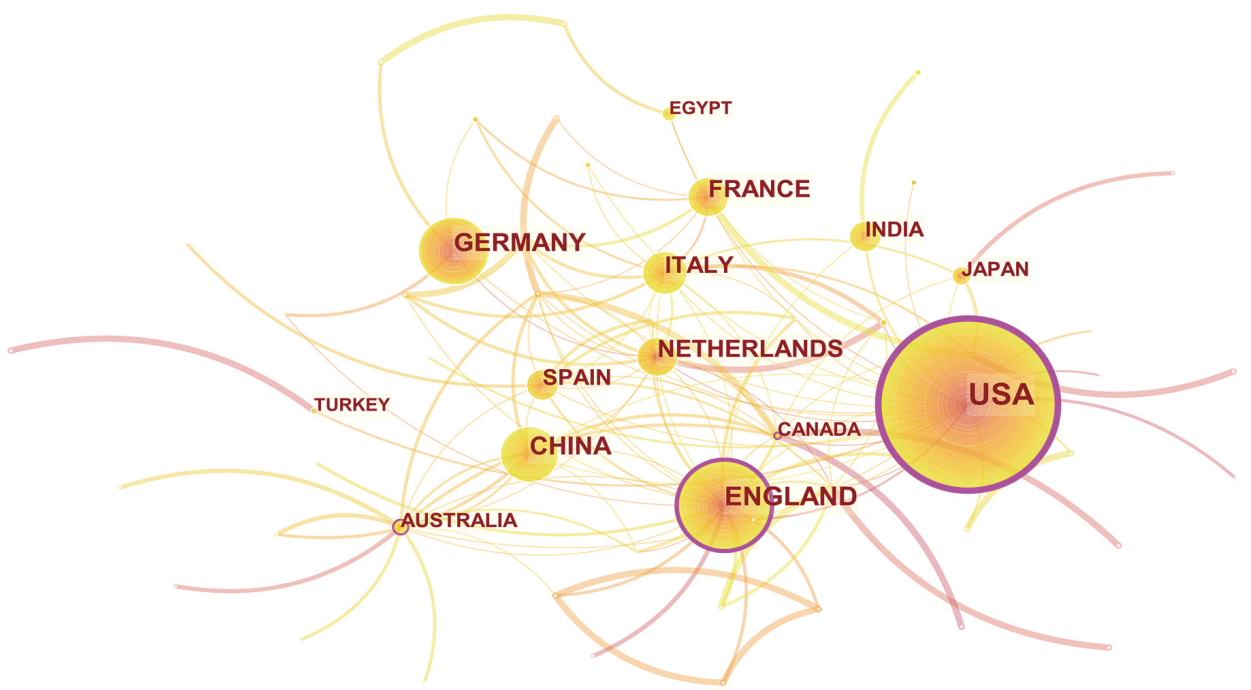

Figure 3 Visualization map of countries. 


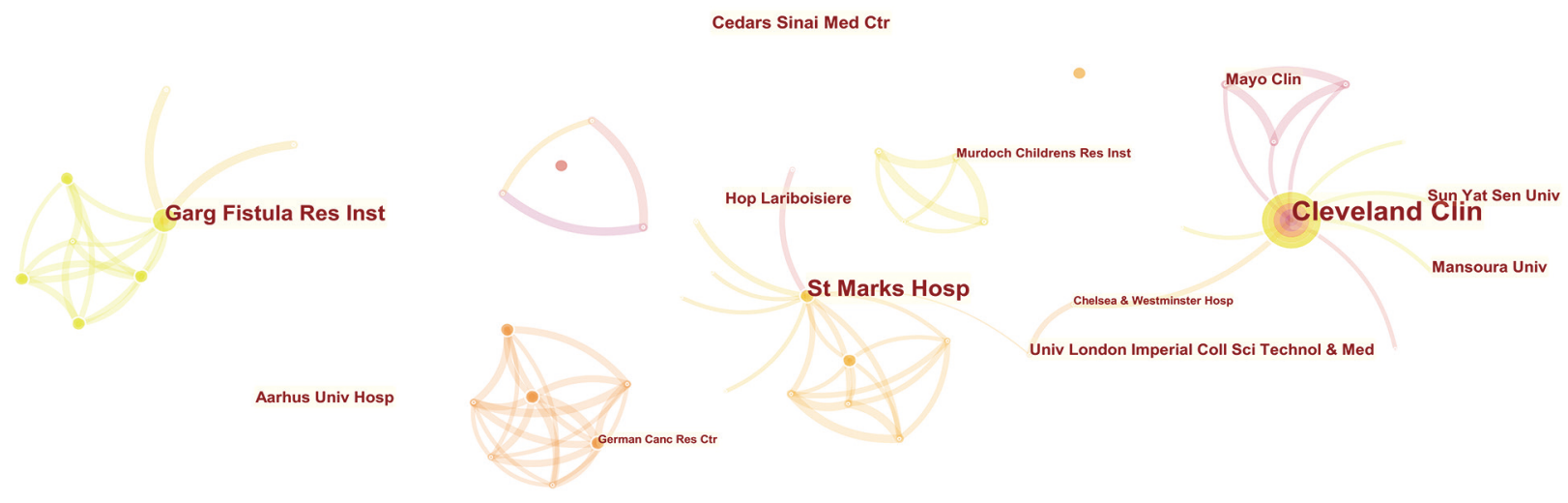

Figure 4 Visualization map of institutions.

publications were Thomas Jefferson University, the Mayo Clinic, the Hospital of Special Surgery, Rush University, and the Cleveland Clinic (see Table 5). The top 4 centrally ranked institutions were Thomas Jefferson University, Tel Aviv University, the University of Melbourne, and Rush University (see Table 6).

\section{Autbors}

In the research field of HAF, the top 3 authors with the most articles published were Garg, Emile, and Kohler (see Table 7). The centrality score of all the authors did not reach 0.1 , and there was little collaboration between authors (see Figure 5). The top 3 cited authors were Parks, Van Koperen, and Williams (see Table 8, Figure 6). The top 3 authors cited in relation to centrality scores were Parks, Fazio, and Williams (see Table 9).

\section{Distribution of journals}

The results of this study included 1,020 papers from 271 journals, of which 13 had published more than 10 papers (see Table 10). A total of 514 papers were published, accounting for $50.39 \%$ of the total number of papers (see Table 10). The top 3 journals based on the frequency of the citations were Dis Colon Rectum, Brit 7 Surg, and Int 7 Colorectal Dis (see Table 11). The top 3 journals based on the centrality of the citations were Lancet, World $\mathcal{F}$ Surg and Surg Gynecol Obstet (see Table 12).

\section{Keywords}

CiteSpace V software analyzed the use of keywords and generated a keyword co-occurrence map (see Figure 7), where node $(N)=374$ (i.e., 374 keywords appeared in these documents). The number of times these keywords appeared in the same articles was $E=2,975$. The top 3 keywords in terms of frequency were "fistula-in-ano", "in-ano", and management (see Table 13), and the top 3 keywords in terms of centrality were "fistula-in-ano", "Crohn's disease", and "fistula" (see Table 14). CiteSpace was used to perform a burst detection on the keywords (see Figure 8).

\section{Discussion}

This study analyzed 1,020 articles and their cited data, and the results showed that the number of articles published and the number of citations on the subject of HAF had generally increased over time. These studies were mainly published in developed countries, such as Europe and the US. There were some cooperative relationships between countries and institutions; however, there was very little cooperation between authors. The literature in this field has mainly been published in the surgical journals of colorectal diseases. The keyword analysis showed that the research mainly focused on the management of anal fistula. Additionally, the distribution of keywords also suggested that in articles in this field, the keywords are relatively inconsistent, and multiple keywords with similar meanings coexist, which is 
Table 3 Top 10 countries for publications

\begin{tabular}{lcc}
\hline Rank & Countries & Publications \\
\hline 1 & USA & 215 \\
2 & England & 95 \\
3 & Germany & 85 \\
4 & China & 76 \\
5 & France & 64 \\
6 & Netherlands & 61 \\
7 & Italy & 55 \\
8 & Spain & 47 \\
9 & India & 40 \\
10 & Japan & 33 \\
\hline
\end{tabular}

Table 4 Centrality for countries

\begin{tabular}{lcc}
\hline Rank & Countries & Centrality \\
\hline 1 & USA & 0.54 \\
2 & England & 0.32 \\
3 & Australia & 0.19 \\
4 & Canada & 0.13 \\
5 & Italy & 0.08 \\
6 & Spain & 0.06 \\
7 & Germany & 0.05 \\
8 & Netherlands & 0.05 \\
9 & Sweden & 0.05 \\
10 & Japan & 0.05 \\
\hline
\end{tabular}

Table 5 Top 10 institutions for publications

\begin{tabular}{lcc}
\hline Rank & Institutions & Publications \\
\hline 1 & Thomas Jefferson Univ & 243 \\
2 & Mayo Clin & 216 \\
3 & Hosp Special Surg & 138 \\
4 & Rush Univ & 114 \\
5 & Cleveland Clin & 103 \\
6 & Duke Univ & 73 \\
7 & Univ Calif San Francisco & 71 \\
8 & NYU & 60 \\
9 & Univ Penn & 54 \\
10 & Sichuan Univ & 46 \\
\hline
\end{tabular}

Table 6 Top 10 institutions for centrality

\begin{tabular}{lcc}
\hline Rank & Institutions & Centrality \\
\hline 1 & Thomas Jefferson Univ & 0.07 \\
2 & Tel Aviv Univ & 0.05 \\
3 & Univ Melbourne & 0.04 \\
4 & Rush Univ & 0.04 \\
5 & Charite Univ Med Berlin & 0.03 \\
6 & Univ Penn & 0.03 \\
7 & Cleveland Clin & 0.03 \\
8 & Hosp Special Surg & 0.03 \\
9 & Mayo Clin & 0.03 \\
10 & Univ Helsinki & 0.02 \\
\hline
\end{tabular}

Table 7 Top 10 authors based on publications

\begin{tabular}{llc}
\hline Rank & Authors & Frequency \\
\hline 1 & Garg PJ & 14 \\
2 & Emile SH & 7 \\
3 & Kohler A & 7 \\
4 & Herold A & 6 \\
5 & Arroyo A & 6 \\
6 & Schoetz DJ & 5 \\
7 & Ailsa Hart A & 5 \\
8 & Parello A & 5 \\
9 & Remzi FH & 5 \\
10 & Yagnik VD & 4 \\
\hline
\end{tabular}

not conducive to a bibliometric analysis.

With the increase in the incidence of related diseases (e.g., AIDS, tuberculosis, and Crohn's disease) or behavior (anal sex), the prevalence of HAF has also shown a significant increase (13). Among them, anal fistula is the most common perianal disease of Crohn's disease (14). The incidence of anal fistula is significantly increased in patients with active intestinal disease, and can be as high as $92 \%$ when the rectum is involved (14). However, most patients with specific anal fistula do not get a timely diagnosis before surgery, which leads to treatment failure. Thus, both scholars at home and abroad agree that the timely identification of the cause of anal fistula and adopting standardized and correct treatment measures can improve 

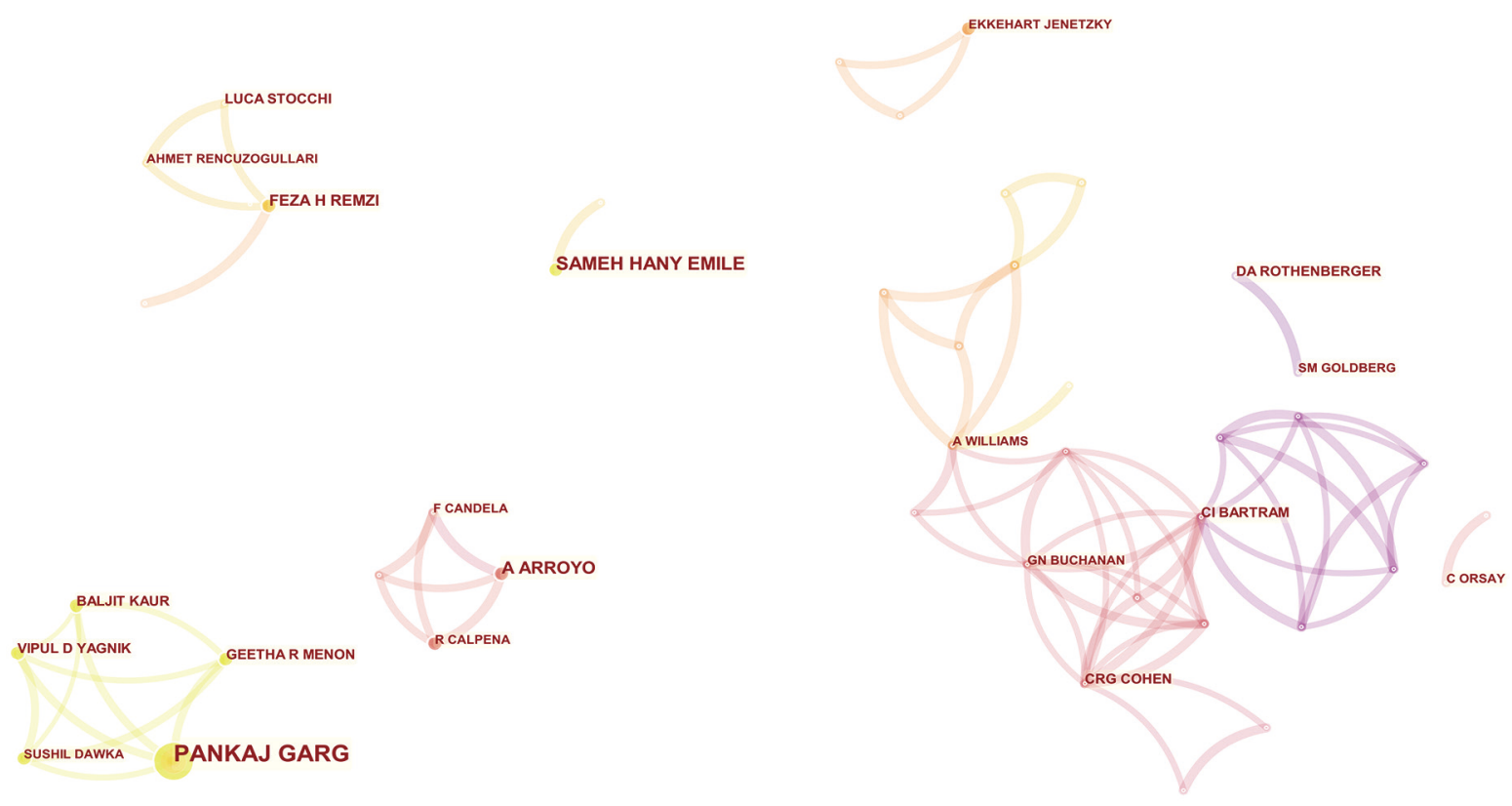

Figure 5 Visualization map of authors' collaborations.

Table 8 Top 10 authors by frequency of co-citations

\begin{tabular}{lcc}
\hline Rank & Authors & Frequency \\
\hline 1 & Parks AG & 307 \\
2 & Van Koperen PJ & 127 \\
3 & Williams JG & 121 \\
4 & Buchanan GN & 120 \\
5 & Garciaaguilar J & 110 \\
6 & Lunniss PJ & 110 \\
7 & Schouten WR & 92 \\
8 & Ortiz H & 90 \\
9 & Ellis CN & 86 \\
10 & Van Der Hagen SJ & 86 \\
\hline
\end{tabular}

the cure rate of anal fistula (7-9).

The main themes of HAFs for patients are pain and local repeated infections and exudations, which reduce patients' quality of life. The long-term prognosis of HAF is relatively good, and generally does not have malignant consequences (15). HAF is not a rare disease; however, there are not many studies on HAF. In this study, the SCI-E database was searched from 1,900 to the present day, and only 1,020 articles were retrieved. Judging from the amount of publications, the medical community has not paid enough attention to this disease. In many medical centers, there are no specialized departments to deal with this kind of problem. Indeed, it is generally treated by general surgery or intestinal surgery departments. The focus of these 2 departments is often on internal organ tumors and acute abdomens. It is difficult for doctors to focus on research of HAF (16). Thus, we found that there were very few high-quality multi-center clinical studies.

There has still been great progress in the treatment of anal fistula; however, the treatment of complex HAF remains very difficult for clinicians. Traditional surgery has a high cure rate, but it has the disadvantage of damaging the anal sphincter. The sphincter-sparing surgery that has emerged over the decades has protected postoperative anal function, but the recurrence rate is significantly higher than that of traditional surgery, which has become a major obstacle to the promotion of sphincter-sparing surgery (17). Thus, looking for a new technology that can effectively retain the function of the sphincter and anus, but can also effectively reduce the recurrence rate has become a popular area of research in the treatment of anal fistula. According to previous studies, predictive factors for recurrence after surgical treatment of high anal 


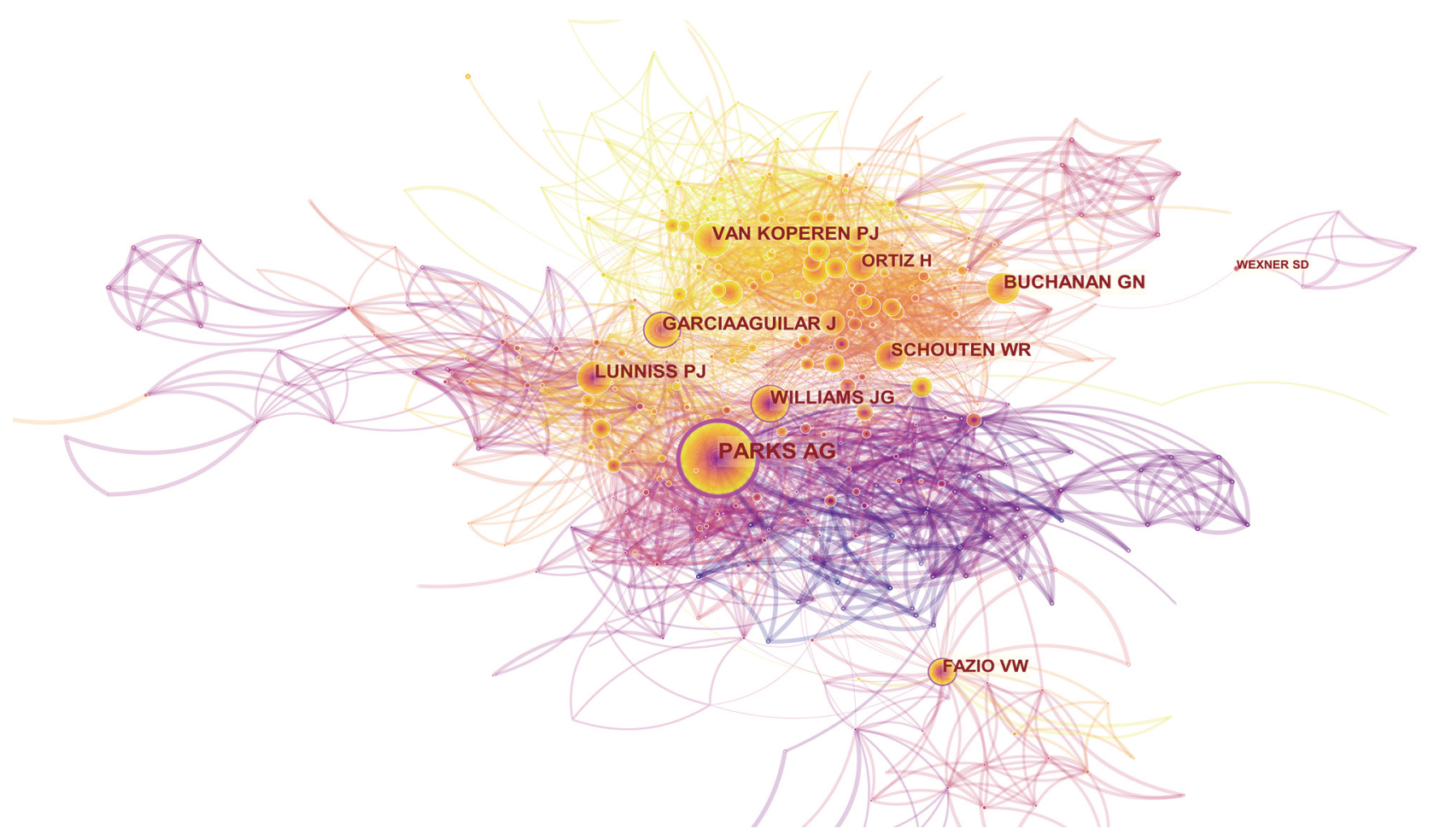

Figure 6 Visualization map of authors by co-citations.

Table 9 Top 10 authors by centrality of co-citations

\begin{tabular}{lcc}
\hline Rank & Authors & Centrality \\
\hline 1 & Parks AG & 0.45 \\
2 & Fazio VW & 0.16 \\
3 & Williams JG & 0.15 \\
4 & Garciaaguilar J & 0.11 \\
5 & Van Koperen PJ & 0.09 \\
6 & Aguilar PS & 0.09 \\
7 & Lunniss PJ & 0.08 \\
8 & Sainio P & 0.08 \\
9 & Ozuner G & 0.07 \\
10 & Law PJ & 0.07 \\
\hline
\end{tabular}

fistula include: internal opening unidentified, horseshoe extensions, prior anal surgery, seton placement surgery, and multiple fistula tract (18).

At present, sphincter-preserving thread-drawing operation, sliding-flap operation, and transsphincteric fistula ligation are the most widely used in clinical practice.
Table 10 Top 10 journals based on the number of articles

\begin{tabular}{lcc}
\hline Journals & Records & $\%$ of 1,020 \\
\hline Diseases of the Colon Rectum & 172 & 16.863 \\
Colorectal Disease & 72 & 7.059 \\
$\begin{array}{l}\text { International Journal of Colorectal } \\
\text { Disease }\end{array}$ & 58 & 5.686 \\
Techniques in Coloproctology & 44 & 4.314 \\
Journal of Pediatric Surgery & 37 & 3.627 \\
British Journal of Surgery & 30 & 2.941 \\
Pediatric Surgery International & 21 & 2.059 \\
Chirurg & 16 & 1.569 \\
Journal of Gastrointestinal Surgery & 15 & 1.471 \\
World Journal of Gastroenterology & 14 & 1.373 \\
\hline
\end{tabular}

Sphincter-preserving thread-drawing surgery can be used to treat complex HAF, and has the advantage of also reducing the risk of anal incontinence (18). This method uses the drainage and foreign body stimulation effects of threadhanging, and discards the chronic strangulation effect that 
Table 11 Top 10 journals by frequency of citation

\begin{tabular}{lcc}
\hline Rank & Journals & Frequency \\
\hline 1 & Dis Colon Rectum & 773 \\
2 & Brit J Surg & 631 \\
3 & Int J Colorectal Dis & 446 \\
4 & Colorectal Dis & 414 \\
5 & Ann Surg & 290 \\
6 & Am J Surg & 284 \\
7 & Tech Coloproctol & 270 \\
8 & Gut & 244 \\
9 & Gastroenterology & 242 \\
10 & Lancet & 199 \\
\hline
\end{tabular}

Table 12 Top 10 journals by centrality of citation

\begin{tabular}{lcc}
\hline Rank & Journals & Centrality \\
\hline 1 & Lancet & 0.16 \\
2 & World J Surg & 0.10 \\
3 & Surg Gynecol Obstet & 0.10 \\
4 & Am J Roentgenol & 0.09 \\
5 & Gastroenterology & 0.08 \\
6 & Radiology & 0.08 \\
7 & Acta Chir Scand & 0.08 \\
8 & New Engl J Med & 0.07 \\
9 & J Pediatr Surg & 0.07 \\
10 & Brit Med J & 0.07 \\
\hline
\end{tabular}

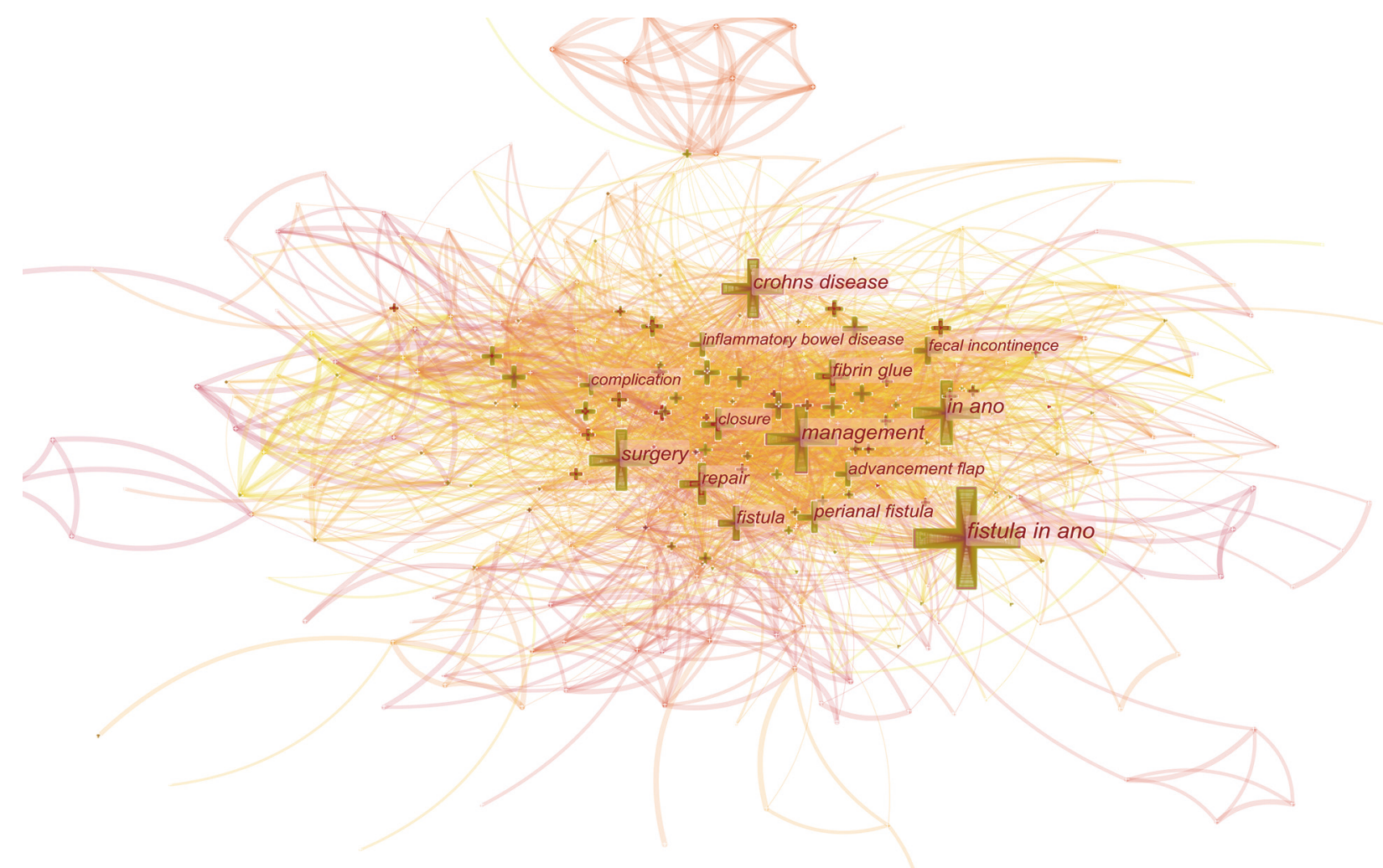

Figure 7 Visualization map of keywords co-occurrence.

causes muscle damage, postoperative pain, and prolonged treatment. It adopts a different view to the traditional one that traditional thread-hanging therapy must cut off the muscle tissue. Under the premise of removing the primary infection foci, thread-hanging without breaking the sphincter has the advantage of protecting the anal function, which is better than the traditional incision thread-hanging method. It achieves the goal of not only curing anal fistula, but also preserving the external anal sphincter completely, thereby protecting the anal function to the utmost extent, 
Table 13 Top 10 keywords by frequency

\begin{tabular}{lcc}
\hline Rank & Keywords & Frequency \\
\hline 1 & Fistula-in-ano & 364 \\
2 & In-ano & 225 \\
3 & Management & 213 \\
4 & Crohn's disease & 178 \\
5 & Surgery & 160 \\
6 & Repair & 101 \\
7 & Fistula & 97 \\
8 & Fibrin glue & 94 \\
9 & Perianal fistula & 93 \\
10 & Advancement flap & 71 \\
\hline
\end{tabular}

Table 14 Top 10 keywords by centrality

\begin{tabular}{lcc}
\hline Rank & Keywords & Centrality \\
\hline 1 & Fistula-in-ano & 0.18 \\
2 & Crohn's disease & 0.14 \\
3 & Fistula & 0.13 \\
4 & Management & 0.12 \\
5 & Surgery & 0.1 \\
6 & Complication & 0.09 \\
7 & Repair & 0.07 \\
8 & Fecal incontinence & 0.07 \\
9 & Anorectal fistula & 0.07 \\
10 & Experience & 0.07 \\
\hline
\end{tabular}

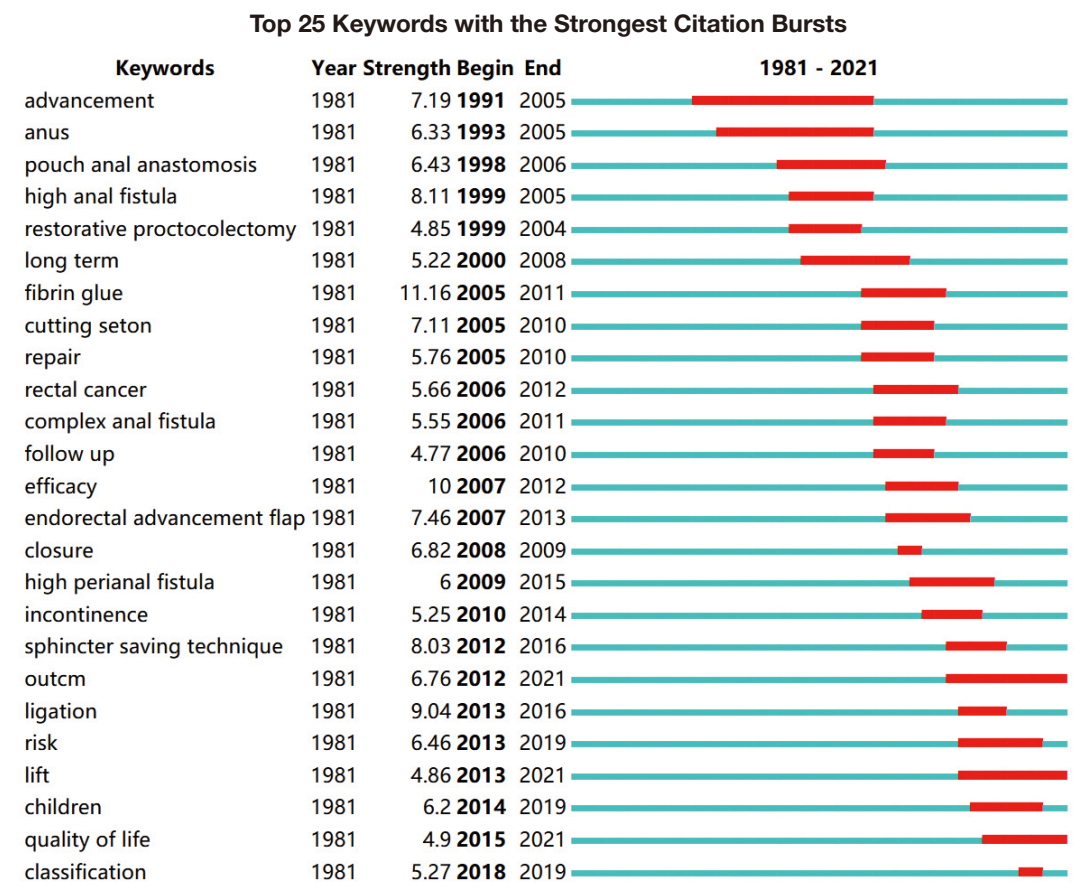

Figure 8 Top 25 keywords with the strongest citation bursts.

which is in line with the development trend for modern minimally invasive surgery (19).

Push-flap surgery is suitable for patients with impaired anal function due to fistula incision, and can also be used to close rectal-urethral or recto-vaginal fistulas (20). This operation cuts off the fistula connected to the rectum after the infection is controlled, and takes normal autologous healthy tissue to cover the internal mouth. A good blood supply and tension-free anastomosis of the moving valve are key to the operation (21).

Another technique involves the transsphincteric fistula tract (the LIFT). The LIFT technique is mainly based on the idea of closing the internal mouth and removing the infected crypt tissue from the intersphincteric plane (22). A 
meta-analysis showed that the success rate of standard LIFT surgery for the treatment of anal fistula is between $61 \%$ and $91 \%$, the healing time is usually 4 to 8 weeks, and there are few complications and very few anal incontinences (23). Both simple and complex transsphincteric anal fistulas can be treated with LIFT surgery $(24,25)$.

VAAFT is an emerging treatment method that brings hope to the treatment of anal fistula (26). It is still unclear whether video assistance is critical to the success of the surgery; some supporters believe that even the lesions missed by MRI can be found using VAAFT. However, there is currently a lack of evidence to support this view, and more detailed research needs to be conducted $(27,28)$.

The laser-ablation treatment of fistula is still in its infancy, and the surgical methods applied at different centers are quite different, a standard technical process has not been established, and there are also great differences in the treatment of the internal mouth $(29,30)$.

Autologous fat-derived stem cells are also a new option for the treatment of complex anal fistula, but to date, there is not enough evidence to prove their effectiveness (31). This technique can be used alone to treat anal fistula by injecting autologous stem cells around the fistula or into the fistula, or it can be combined with fibrin glue or push flaps $(31,32)$.

Thus, many novel surgical methods have emerged in recent years that have brought new hope to the surgical treatment of anal fistula; however, the effectiveness of these emerging surgical methods cannot be evaluated based on the current data or compared with the classic sphinctersparing surgery. As we are still in the early days, multicenter, large sample, parallel randomized controlled trials need to be conducted (33).

This study had a number of limitations. This study only searched for articles in the SCI-E, which is a common databased used for bibliometric analysis; however, other databases may include articles that do not appear in the SCI-E. Thus, some documents may have been missed. Second, inconsistences in the keywords of different publications may have had an effect on the analysis of utility and the centrality of the keywords.

\section{Acknowledgments}

Funding: None.

\section{Footnote}

Conflicts of Interest: All authors have completed the ICMJE uniform disclosure form (available at https://dx.doi. org/10.21037/apm-21-3190). The authors have no conflicts of interest to declare.

Ethical Statement: The authors are accountable for all aspects of the work in ensuring that questions related to the accuracy or integrity of any part of the work are appropriately investigated and resolved.

Open Access Statement: This is an Open Access article distributed in accordance with the Creative Commons Attribution-NonCommercial-NoDerivs 4.0 International License (CC BY-NC-ND 4.0), which permits the noncommercial replication and distribution of the article with the strict proviso that no changes or edits are made and the original work is properly cited (including links to both the formal publication through the relevant DOI and the license). See: https://creativecommons.org/licenses/by-nc-nd/4.0/.

\section{References}

1. Zanotti C, Martinez-Puente C, Pascual I, et al. An assessment of the incidence of fistula-in-ano in four countries of the European Union. Int J Colorectal Dis 2007;22:1459-62.

2. Manookian CM, Sokol TP, Headrick C, et al. Does HIV status influence the anatomy of anal fistulas? Dis Colon Rectum 1998;41:1529-33.

3. Zhang Y, Li F, Zhao T, et al. Efficacy of video-assisted anal fistula treatment combined with closure of the internal opening using a stapler for Parks II anal fistula. Ann Transl Med 2020;8:1517.

4. Farag AFA, Elbarmelgi MY, Mostafa M, et al. One stage fistulectomy for high anal fistula with reconstruction of anal sphincter without fecal diversion. Asian J Surg 2019;42:792-6.

5. Wang D, Yang G, Qiu J, et al. Risk factors for anal fistula: a case-control study. Tech Coloproctol 2014;18:635-9.

6. Pigot F. Treatment of anal fistula and abscess. J Visc Surg 2015;152:S23-9.

7. Clinical Guidelines Committee, Colorectal Surgeons Branch of Chinese Medical Doctor Association. Consensus of Chinese experts on the diagnosis and treatment of anal fistula (2020). Zhonghua Wei Chang Wai Ke Za Zhi 2020;23:1123-30.

8. Amato A, Bottini C, De Nardi P, et al. Evaluation and management of perianal abscess and anal fistula: SICCR position statement. Tech Coloproctol 2020;24:127-43. 
9. Ommer A, Herold A, Berg E, et al. German S3 guidelines: anal abscess and fistula (second revised version). Langenbecks Arch Surg 2017;402:191-201.

10. Zheng L, Shi Y, Zhi C, et al. Loose combined cutting seton for patients with high intersphincteric fistula: a retrospective study. Ann Transl Med 2020;8:1236.

11. Yu Y, Li Y, Zhang Z, et al. A bibliometric analysis using VOSviewer of publications on COVID-19. Ann Transl Med 2020;8:816.

12. Wrigley J, Carden V, von Isenburg M. Bibliometric mapping for current and potential collaboration detection. J Med Libr Assoc 2019;107:597-600.

13. Panés J, Rimola J. Perianal fistulizing Crohn's disease: pathogenesis, diagnosis and therapy. Nat Rev Gastroenterol Hepatol 2017;14:652-64.

14. Sica GS, Di Carlo S, Tema G, et al. Treatment of perianal fistula in Crohn's disease. World J Gastroenterol 2014;20:13205-10.

15. Owen HA, Buchanan GN, Schizas A, et al. Quality of life with anal fistula. Ann R Coll Surg Engl 2016;98:334-8.

16. Limura E, Giordano P. Modern management of anal fistula. World J Gastroenterol 2015;21:12-20.

17. Feroz SH, Ahmed A, Muralidharan A, et al. Comparison of the Efficacy of the Various Treatment Modalities in the Management of Perianal Crohn's Fistula: A Review. Cureus 2020;12:e11882.

18. Mei Z, Wang Q, Zhang Y, et al. Risk Factors for Recurrence after anal fistula surgery: A meta-analysis. Int J Surg 2019;69:153-64.

19. Mujukian A, Zaghiyan K, Banayan E, et al. Outcomes of Definitive Draining Seton Placement for Complex Anal Fistula in Crohn's Disease. Am Surg 2020;86:1368-72.

20. Balciscueta Z, Uribe N, Balciscueta I, et al. Rectal advancement flap for the treatment of complex cryptoglandular anal fistulas: a systematic review and metaanalysis. Int J Colorectal Dis 2017;32:599-609.

21. Bondi J, Avdagic J, Karlbom U, et al. Randomized clinical trial comparing collagen plug and advancement flap for trans-sphincteric anal fistula. Br J Surg 2017;104:1160-6.

22. Rojanasakul A, Pattanaarun J, Sahakitrungruang C, et al. Total anal sphincter saving technique for fistula-in-ano; the ligation of intersphincteric fistula tract. J Med Assoc
Thai 2007;90:581-6.

23. Hong KD, Kang S, Kalaskar S, et al. Ligation of intersphincteric fistula tract (LIFT) to treat anal fistula: systematic review and meta-analysis. Tech Coloproctol 2014;18:685-91.

24. Placer Galán C, Aguirre I, Pastor T, et al. LIFT procedure for posterior fistula-in-ano. Are outcomes good enough? A systematic review and meta-analysisis of observational studies. Cir Esp (Engl Ed) 2021;99:183-9.

25. Emile SH, Khan SM, Adejumo A, et al. Ligation of intersphincteric fistula tract (LIFT) in treatment of anal fistula: An updated systematic review, meta-analysis, and meta-regression of the predictors of failure. Surgery 2020;167:484-92.

26. Lopez MPJ, Onglao MAS, Monroy Iii HJ. Initial Experience With Video-Assisted Anal Fistula Treatment in the Philippines. Ann Coloproctol 2020;36:112-8.

27. Giarratano G, Shalaby M, Toscana C, et al. Video-assisted anal fistula treatment for complex anal fistula: a long-term follow-up study. Colorectal Dis 2020;22:939-44.

28. Garg P, Singh P. Video-Assisted Anal Fistula Treatment (VAAFT) in Cryptoglandular fistula-in-ano: A systematic review and proportional meta-analysis. Int J Surg 2017;46:85-91.

29. Giamundo P, Esercizio L, Geraci M, et al. Fistula-tract Laser Closure (FiLaC ${ }^{\mathrm{TM}}$ ): long-term results and new operative strategies. Tech Coloproctol 2015;19:449-53.

30. Lauretta A, Falco N, Stocco E, et al. Anal Fistula Laser Closure: the length of fistula is the Achilles' heel. Tech Coloproctol 2018;22:933-9.

31. Panés J, García-Olmo D, Van Assche G, et al. Expanded allogeneic adipose-derived mesenchymal stem cells (Cx601) for complex perianal fistulas in Crohn's disease: a phase 3 randomised, double-blind controlled trial. Lancet 2016;388:1281-90.

32. Carvello M, Lightner A, Yamamoto T, et al. Mesenchymal Stem Cells for Perianal Crohn's Disease. Cells 2019;8:764.

33. Gardner IH, Siddharthan RV, Tsikitis VL. Benign anorectal disease: hemorrhoids, fissures, and fistulas. Ann Gastroenterol 2020;33:9-18.

(English Language Editor: L. Huleatt)
Cite this article as: Li X, Zhi C, Shi Y, Cheng Y, Zheng L. Research on high anal fistula: a bibliometric analysis. Ann Palliat Med 2021;10(11):11492-11503. doi: 10.21037/apm-213190 